\title{
Research on Problems and Countermeasures of China's Regional Economic Development in the New Era
}

\author{
Jincao Qin \\ School of Marxism, Yangtze University, Jingzhou, 434023, China \\ 1783944881@qq.com
}

Keywords: new era; regional economic development; problems; countermeasures

\begin{abstract}
The new era requires new development concepts, and the implementation of coordinated regional development strategy is one of them. In recent years, the west development, the rejuvenation of the old industrial base in northeast China, the promotion of the rise of the central region, and the development of innovation in the eastern region have been implemented in succession, which have effectively promoted regional economic development. However, the unbalanced development of the regional economy has become more and more obvious, causing structural contradictions and various social problems at the macroeconomic level in China. This article is guided by relevant theories of regional economic development, profoundly interprets the connotation of regional economy, analyzes the problems in Chinese regional economic development, proposes the new era to promote Chinese regional economic development, promotes Chinese economy to embark on the healthy development route and serves for the coordinated development of the regional economy.
\end{abstract}

\section{Introduction}

The report of the 19th National Congress of the Chinese Communist Party pointed out that China has developed a new historical position and socialism with Chinese characteristics has entered a new era. This major judgement is guided by the Marxism of the times, with all-round and pioneering achievements since the 18th CPC National Congress, as well as deep-rooted and fundamental changes as the realistic basis for realizing the history of integrating Marxism with China's reality. A profound understanding of the scientific nature of this major judgment is of great significance for accurately grasping the historical position of contemporary China and establishing the great era of socialist construction with Chinese characteristics in the new era under a firm and confident attitude. The report of the 19th National Congress pointed out that China's economy has shifted from a high-speed growth stage to a high-quality development stage. It is now in the period of tackling the transformation of development methods, optimizing the economic structure, and transforming the growth momentum. The construction of the modern economic system is an urgent requirement and a strategic goal to step over the juncture. .

The new era requires new development concept, and the implementation of coordinated regional development strategy is one of them. Increase efforts to support the accelerated development of the old revolutionary base areas, ethnic areas, boarder areas, and poverty-stricken areas, strengthen measures to promote the development of the western region to form the new pattern, deepen reforms to accelerate the rejuvenation of old industrial bases in the northeast, give play to the advantages to promote the rise of the central region, and lead innovation to lead the east regional optimization of development, the establishment of more effective regional coordination and development of new mechanisms. Urban groups will be the main part to build the coordinated urban development pattern for large, medium and small cities and small towns, and to speed up the urbanization of the agricultural transfer population. Relieve Beijing's non-capital function, promote the coordinated development of Beijing, Tianjin and Hebei, and establish a high starting point for planning and high standards for Xiongan New District. We will promote the development of the economic belt of the Yangtze River by focusing on the protection and non-development. Support the 
economic transformation and development of resource-based regions. Accelerate the development of border areas and ensure the consolidation of border areas and border security. Adhere to the overall planning of land and sea, and speed up the construction of the marine power. In the face of the development concept of the new era, it is necessary to recognize the problems existing in the regional economic development in China and take corresponding countermeasures to promote the coordinated development of the regional economy.

\section{Connotations of Regional Economic}

Regional economy refers to the complex production produced by the interaction of internal factors of economic development and external conditions within a certain area. Regional development entities have a certain area as a scope and are closely integrated with economic factors and their distribution. The regional economy reflects the objective laws of the economic development in different regions as well as the interrelationship between connotation and extension. All regions have unique natural, social, and cultural conditions, which has led to differences in the level of economic development, industrial structure, and production layout in various regions. The regional economy is based on the division of labor division theory and superiority theory, and the region is the spatial carrier. Based on the existing social conditions, economic levels, humanities, and natural resources in the region, the total economic output is expanded to the utmost, and the structure is reasonable and the leading industry is outstanding, sustainable development and a distinctive regional economy. Regional economies are holistic, relevant, relatively independent, and spatially diverse, with differences showing distinctive features.

(1) The regional economy depends on the space of human economic activities. The existence of the regional economy must rely on certain geographical space. Different economic activities have obvious spatial selectivity for specific geographical conditions, and the differences in natural resources have created regional differences and regional advantages.

(2) The incomplete mobility of production factors has led to differences in economic activities. Different factors of production have spawned different economic activities. The distribution of natural elements such as land, water, minerals and energy is not balanced. The liquidity is inherently insufficient and the flow costs are high. Social elements such as capital, technology, talent, and information are highly mobile, but they are affected by many factors such as geographical barriers, policy systems, and the human environment, and their liquidity is reduced.

(3) Market rules and the guiding role of government policies have prompted the formation of a regional economy, to some content . With the increasing development of the market economy, the role of market rules has led to the allocation of limited economic resources to regions with natural resources. As time passes, this resource advantage will gradually turn into the economic advantage, forming the different regional economy. At the same time, the government's tilting policy has increased the economic vitality of specific regions, attracted the accumulation of production factors and economic entities in the surrounding areas, and formed the regional economy.

\section{Related Theories of Regional Economic Development Research}

There are many theories of regional economic development. The research in this paper mainly involves the following four related theories:

(1) Gradient transfer theory. Innovation activities are decisive factors that determine the gradient of regional development, and innovation activities mostly occur in high gradient regions. Production activities have gradually shifted from high-gradient regions to low-gradient regions, and it is advocated that developed regions should first accelerate development, and then shift industries and factors to more developed areas and less-developed regions so as to drive the economic development of the entire region.

(2) Radiation theory. Capital, talent, technology, and markets in areas with relatively high levels of economic development and modernization are flowing to regions with relatively backward economic development, as well as the dissemination of ideological concepts, modes of thinking, 
and lifestyle habits, replacing old ones that are contrary to modernization. Customary forces, thereby further improving the efficiency of the allocation of economic resources.

(3) Growth pole theory. In the process of economic growth, different industries have different growth rates. The fastest-growing industries are leading industries and innovative industries, all of which are clustered in certain specific areas. These areas that have gathered leading industries and innovative industries are called "growth poles". After giving priority to development, it will spread to the surrounding areas to form a powerful radiation effect and drive the development of the surrounding areas.

(4) Comparative advantage theory. A country can be divided into several regions. In the process of economic development, each region has differences in natural resources, development basis and humanities conditions. Since there are differences between regions, there must be certain advantages and disadvantages. An objective analysis of the comparative advantages of each region is the basic basis for formulating policies for regional economic development and economic distribution.

\section{Existing problems of China's Regional Economic Development}

Due to factors such as the natural environment, development history, cultural foundation, investment environment, and national policies, there is a gap in regional economic development, and this gap has further widened, resulting in a series of problems that affect the development of the entire national economy. The current regional experience and development issues are summarized as follows:

(1) The phenomenon of structural homogenization of the regional industry is still serious, which hinders the formation of regional specialization. The division of labor in the "resources-processin" vertical region hinders the coordinated development of regional industries and the optimization and upgrading of the structure, which is not conducive to the regional economy moving toward a higher level; the interregional cooperation barriers have not been completely broken, and contradiction and conflicts still exist; with regard to these same industries, all regions have positioned the direction of development in the industrial sector. There is the lack of specialized division of labor among the regions, which affects the effective division of labor and rational distribution of industrial development.

(2) The regional interest contradiction coordination mechanism is not perfect, which restricts the realization of the common goals of regional development. First, the lack of sharing mechanisms for fiscal revenue generated by major projects or enterprises across regions. Second, the tax transfer mechanism for industrial transfer is not perfect. Third, cross-regional public goods supply lacks cost sharing mechanisms and benefit compensation mechanisms. Cross-regional public goods have not received much attention for a long time, especially in the area of environmental protection, and there is the phenomenon of shifting on pollution control costs.

(3) "Backward disease" and "expansion disease" coexist, which is not conducive to the sustainable development of the regional economy. The "backward disease" mainly exists in the economically underdeveloped Central and Western regions, with low levels of economic, social, and technological development, slow economic growth, underdeveloped cultural undertakings, low living standards, and low local fiscal revenue. "Expansion disease" mainly exists in the eastern region where the economy is more developed, with excessive concentration of industries and populations, rapid expansion of regional scale, rising production and living costs, and declining regional comprehensive competitiveness.

(4) The gap in regional economic development has further widened and the phenomenon of local separatism remains serious. Since the reform and opening up, with the rapid economic development in the eastern region, a large number of production factors have flowed to the eastern region, but the gradient transfer of industries from the eastern region to the central and western regions has not been realized, and the absolute gap in economic development has continued to widen. Under the background of an increasingly widening regional disparity, there are serious local protectionism, 
and the administrative system is fragmented, making it difficult to achieve optimal allocation of resources and economic integration.

(5)The hematopoietic function in underdeveloped areas is insufficient, and the "resource-for-growth" model is widespread. The infrastructure construction in underdeveloped areas is backward, preferential policies have no absolute advantage, lack of sufficient attractiveness, backward industrial structure, and lack of attraction to external funds. Lack of talent, lack of research funds, and weak economic growth. The growth in the environment and resources will result in a continuous decline in investment efficiency and an increase in environmental pressure. The sustainable development of the regional economy will face more serious problems.

(6) Single pursuit of economic benefits, ignoring ecological and social benefits. In the process of industrialization in the eastern region, excessive emphasis was placed on economic development and basically no demands were placed on the environment. As a result, high costs are now being used to control pollution. The development of the central and western regions is still on the way to the east, ignoring the protection of the ecological environment and pollution, resulting in land consolidation, grassland desertification, floods, and other disasters. The intrinsic deployment mechanisms of the various elements of the natural environment have been misaligned and the natural ecological environment has deteriorated.

\section{Countermeasures of China's Regional Economic Development in the New Era}

The 19th National Congress of the Communist Party of China's flag was oriented, open a new hard drive map, made series of major judgments, gave the party and the coutry a new era of development, and provided the era's coordinates for leading the new era of China's regional economic development towards a new journey and opening up new realms. With the theoretical basis, it proposes value orientation, goals and tasks. China's economic construction must be based on the new era, realize new judgments, plan new ideas, and urge new actions to fully open up a new journey for regional economic development. Guided by the spirit of The 19th National Congress of the Communist Party of China, and in response to the problems existing in China's regional economic development, we have participated in relevant documents. The countermeasures proposed in this paper to promote regional economic development in China are as follows:

(1) Transform government functions and strengthen the government's macro-control efforts. The government behavior as the dominant regional economic and social development is the main aspect that restricts the pattern of regional interest relations. The structural contradiction that has been prominent for a long time is actually the contradiction between the administrative region and the economic zone. To eliminate these conflicts, the most important thing is to change government functions. The local government must be free from the disputes over rights and interests, focus on the long-term interests and overall interests of regional development, and provide services for strengthening regional economic cooperation and cooperation. The government plays an important role in the coordinated development of the regional economy. The coordinated development of the regional economy requires not only an effective market regulation but also the government's "tangible hand", resolved through macro-control. Therefore, while giving play to the role of the market in resources, we must strengthen macroeconomic regulation and control to eliminate "market failures" caused by excessive regional disparities.

(2) Attach importance to the overall and integrated nature of the regional economic development strategic system, and do a good job in the organization and management of strategic formulation. The strategy of regional economic development means that in a relatively long period of time, based on the assessment of regional economic and social development, taking into account the various aspects of regional economic and social development, the guiding ideology for the regional economic development, the objectives to be achieved, and the The priorities to be solved and the stages of the required experience, as well as the total planning and total decision-making that must be taken, are the top-level design of regional economic development. In the formulation process, according to the internal and external environment and basic conditions of the region, it reflects the systematic thinking of centralized guidance, unified layout and decentralized implementation. After 
rigorous work initiation, investigation and research, program demonstration, preparation plan, cost budget, work development, process control, and job closure, etc., they are organized in accordance with the modern project management system and processes.

(3) Focusing on the optimization of regional economic structure, we must focus on improving the quality of regional economic development. In the real society, the quality of regional economic development involves the ecological environment impact and protection, resource consumption and occupation, resource allocation efficiency, market order and economic environment, and related social issues in the process of regional economic growth. The improvement of economic quality, the social and personal welfare of a region, the actual quality of life of the residents, the degree of economic stability, the improvement of the natural ecological environment, and the degree of political and cultural modernization are the ultimate signs of economic development. The quality of economic development is constantly improving. The foundation of social sustainable development. All regions must grasp the important period of opportunity for regional economic and social development goals, base on their local advantages and industrial bases, carry out structural adjustment of the regional economy, and upgrade the quality of regional economic development.

(4) Overall regional development planning, establish regional interest adjustment mechanism. The eastern region should continue to play an engine role in guiding the country's economic development, giving priority to the development of high-tech industries, export-oriented industries and modern service industries, and play a major role in participating in international competition and cooperation. Most of the central regions are large agricultural provinces, making full use of their east-west and the north-south, located in a favorable position in the center of China and the water transportation network, and "lead west to east" to accelerate the pace of traditional industrial technological transformation and agricultural modernization, and strive to achieve it to become another main driving force for the development of the national economy. The western region seeks to achieve breakthrough development in infrastructure and ecological environment construction in the western region through the construction projects of West-East Gas Transmission, West-East Electricity Transmission, South-to-North Water Transfer and the Qinghai-Tibet Railway, and the restoration of forests and natural forests to build a broader platform.

(5) Ensure cooperation areas, promote gradient development, and take the route of exogenous development. Gradient development conforms to economic laws and meets the characteristics of informatization, networking, and global economic development. From the perspective of the "Pan-Pearl River Delta", the "Pan-Yangtze River Delta", and the "Bohai Bay", the development of the regional region for the axis is mainly driven by enterprises and local governments in the early stage. It needs to further expand the scope of cooperation, deepen the depth of cooperation, and coordinate and remedy the situation. The blind spots of market failures establish an effective cooperation mechanism. The information and capital advantages of the "Pan-Pearl River Delta", the technological and educational advantages of the "Pan-Yangtze River Delta", and the talents and transport advantages of the "Bohai Bay" must be further regionalized to form a regional hierarchy with plates, focus, and features. The industrial system has fully promoted the development of the regional economy. The timely transfer of industries is the need for adjustment of the industrial structure in the developed economic zones. The gradient transfer of the "Pan-Pearl River Delta", the "Pan-Yangtze River Delta", and the "Bohai Bay" is already an inevitable trend and meets the requirements of objective development.

(6) Give play to regional advantages and strengthen inter-regional cooperation. Regardless of economic development or technical level, the eastern region is significantly stronger than the central and western regions. In the eastern region, foreign capital, resources, and markets are attracted, relying on high and new technologies, and intensive operations, focusing on the development of industries with low resource consumption, high added value, and high technological content. In the central and western regions, vigorously develop agriculture, forestry, animal husbandry and processing industries, develop energy and mineral resources, and turn resource advantages into economic advantages. In the northeast region, equipment is updated, technology is improved, product competitiveness is improved, and equipment manufacturing industry is vigorously 
developed. Strengthen inter-regional cooperation. All regions should downplay the consciousness of administrative divisions, eliminate local protectionism, ensure the smooth flow of people, logistics, capital, and information flow in all regions, promote the rational allocation of production factors among regions, and ensure the smooth production of advanced factors in the eastern region to inflow into the central and western regions.

(7) Give play to the impetus of scientific and technological innovation to regional economic development, and pay attention to the accumulation of human capital. Entering the new era, science and technology are increasingly showing the major role in transforming society. Regional economic development is increasingly dependent on scientific and technological strength and innovation capabilities. It is necessary to gradually realize the innovation model based on introduction, and shift leapfrogging to independent innovation to improve the overall competitiveness of the regional industry. Increase investment in science and technology, increase development stamina, and promote the development of high-tech industries. Actively encourage qualified companies to cooperate with universities or scientific research institutions, develop high-tech industries through technological innovation, adjust and optimize industrial structure, increase efficiency, and establish regional technological innovation advantages. Science and technology should be innovative, talents are the key. We must pay attention to the accumulation of human capital, pay attention to the development of education, especially higher education, and provide support for the development of talent for regional economic development and technological innovation.

\section{References}

[1] Y. F. Wang, "Exploring the connotation, mechanism and evaluation of regional economic development," Journal of Chifeng University (Natural Science Edition), vol. 30, no. 12, pp. 114-116, 2014.

[2] W. Shang, "The problems and Countermeasures of China's regional economic cooperation and development," New West, vol. 13, no. 12, pp. 47-48, 2018.

[3] Y. H. Yang, "Problems and Countermeasures of regional economic development in China," Popular Science, vol. 53, no. 5, pp. 175-176, 2011.

[4] M. Lu, "Regional economic development situation, problems and Countermeasures in Liaoning in the new era," Liaoning Economy, vol. 37, no. 2, pp. 56-59, 2018.

[5] Zhang Qing, "The Research on Influence of Industrial Clusters on Regional Economic Development," IERI Procedia, vol. 3, no. 1, pp. 206-212, 2012.

[6] Karen Chapple, Sergio Montero, "From learning to fragile governance: Regional economic development in rural Peru," Journal of Rural Studies, vol. 44, no. 4, pp. 143-152, 2016.

[7] Jian Gao, Tao Zhou, "Quantifying China's regional economic complexity," Statistical Mechanics and its Applications, vol. 492, no. 15, pp. 1591-1603, 2018.

[8] X. Yu, M. L. Hong, "Problems and Countermeasures Study of Ecological System for Starting a Business to Promote Regional Economic Study," Seeking Truth, vol. 43, no. 6, pp. 60-66, 2016. 